\title{
Self Efficacy and Work Performance: A Theoretical Framework of Albert Bandura's Model, Review of Findings, Implications and Directions for Future Research
}

\author{
Manasseh N. Iroegbu \\ Department of psychology, University of Uyo, Uyo, Nigeria
}

Email address:

manassehiroegbu@yahoo.com

To cite this article:

Manasseh N. Iroegbu. Self Efficacy and Work Performance: A Theoretical Framework of Albert Bandura's Model, Review of Findings, Implications and Directions for Future Research. Psychology and Behavioral Sciences. Vol. 4, No. 4, 2015, pp. 170-173.

doi: $10.11648 /$ j.pbs.20150404.15

\begin{abstract}
The article examined the relationship between Self Efficacy and Work Performance using Albert Bandura's Social Cognition Theory as a theoretical framework. Bandura's main proposition was that individuals with high self efficacy believe in themselves and go on to exhibit high performance while individuals with low self efficacy do not have confidence in themselves and end up with low performance. The review of Iiterature revealed that findings have been varried with some studies having a positive relationship between self effficacy and work performance, some a negative relationship and some no relationship between the variables. However it was discovered from the studies that several interveining variables such as nature of the task, inteligence, personality, skill level, motivation, supervision, training, level of the worker, education, etc mediated the relationship between self efficacy and work performance. Thus, Bandura's Social Cognition theory has great implications for the world of work and performance in organisations, but may not necessarily act in isolation, but in conjunction with other organisational variables to foster optimum job performance.
\end{abstract}

Keywords: Work Performance, Self Efficacy, Organisations, Social Cognition Theory

\section{Introduction}

\subsection{Theoretical Framework}

In the past 20 years, there has been a growing research interest in the contribution which social learning theory (or social cognition theory) can make in the area of work performance. For example, in an earlier review of personnel training and development, Campbell believed there was promise in Bandura's description of training methodologies which included both modeling and vicarious learning, which have become central constructs in Bandura's social cognition theory framework. Since that time, extensive empirical evidence has given strong support to the validity and utility of social learning theory and to the existence of strong links between task performance, motivation, and self-efficacy. Self-efficacy, a social cognition construct (social learning) which refers to a person's self-beliefs in his or her ability to perform specific tasks, has been shown to be a reliable predictor of both motivation and task performance, and to influence personal goal setting.
According to Bandura's description of the human cognitive self-regulation system, self-efficacy beliefs are the most central and pervasive influence on the choices people make, their goals, the amount of effort they apply to a particular task, how long they persevere at a task in the face of failure or difficulty, the amount of stress they experience and the degree to which they are susceptible to depression.

Self-efficacy is a central tenet of Albert Bandura's (1977) social cognitive theory. Self-efficacy is the belief, or confidence, that one can successfully execute a behaviour required to produce an outcome such that the higher the level of self-efficacy, the more an individual believes he or she can execute the behaviour necessary to obtain a particular outcome (Bandura, 1977). One tends to avoid situations believed to exceed his or her abilities and get involved, without hesitation, in activities for which he or she feels capable (Bandura, 1977). A central idea posed in social cognitive theory is that success experiences raise selfefficacy but repeated failures lower self-efficacy. Moreover, enhanced self-efficacy, secondary to repeated successes often generalizes to new situations (Bandura, 1977). 
Bandura (1994) described self-efficacy as a person's judgment of his or her ability to achieve or accomplish an action and supports the importance of a determinant for behavioural performance. The beliefs that people with high self-efficacy hold influence on what they feel and think about others, thus motivating them to action. In other words, individuals who are efficacious and capable of performing a given behaviour are often found to be socially engaged in rendering supportive services to peers, family relatives and others in a target behaviour more frequently than those ones who feel unskilled (Bandura, 1994; Schwarzer \& Luszczyuska, 2007).

For instance, self-efficacy is related to specific situations and tasks, than personality trait, this is because it is rather a temporary characteristics, because individuals sometimes identify behaviours that they would like to change and activities in which they would like to participate; however, most people do realize that a gap exists between their desire to make a change and their ability to actually put that desire into action. Self-efficacy plays a critical role in closing the gap between thought and action, aiding individuals in moving towards behavioural changes. People who receive and accept positive verbal encouragement from others demonstrate a reduction in self-doubt and therefore present a higher-self efficacy. Acquiring the ability to minimize negative thoughts and keep a positive outlook when facing difficult or challenging tasks help individuals achieve a level of self-efficacy and lower their negative emotional arousal as well as social relationships (Bandura, 1994; 1997; Luszynska \& Scwarzer, 2008; Schwarzar \& Luszcynska, 2007).

Strong self-efficacy beliefs enhance human accomplishment and personal well-being in many ways. People with a strong sense of personal competence in a domain approach difficult task in that domain as challenges to be mastered rather than as dangers to be avoided; have great intrinsic interest in activities, set challenging goals and maintain a strong commitment to them, heighten their efforts in the face of failure, more easily recover their confidence after failures or setbacks and attribute failure to insufficient effort or deficient knowledge and skills which they believe they are capable of acquiring. High self-efficacy helps create feelings of serenity in approaching difficult tasks and activities.

Conversely, people with low self-efficacy may believe that things are tougher than they really are, a belief that fosters stress, depression and a narrow vision of how best to solve a problem. As a result of these influences, self-efficacy beliefs are strong determinants and predictors of the level of accomplishment that individual finally attain. For these reasons, Bandura (1997) had made strong claim that beliefs of personal efficacy constitute the factors of human agency while, self-efficacy in general refers to one's confidence in executing courses of action in managing a wide array of situations. Work self-efficacy assesses workers' confidence in managing work place experiences. The theoretical underpinning is that individuals with higher work selfefficacy are more likely to look forward to and to be successful in work place performance.

To what extent do empirical evidence, studies and findings support this theoretical framework of Bandura 1977 social cognitive theory. Here in lies the rationale for this review: to authenticate Bandura's theoretical framework and or identify other variables or constructs that may be directly or indirectly involved in the self-efficacy/work performance relationships.

\subsection{Review of Findings}

Lunenburg (2011) posited that self-efficacy (beliefs about one's ability to accomplish specific tasks) influences the tasks employees choose to learn and the goals they set for themselves. Self-efficacy also affects employees' level of effort and persistence when learning difficult tasks. Four sources of self-efficacy are past performance, vicarious experience, verbal persuasion, and emotional cues. Mainly due to the work of Albert Bandura, self-efficacy has a widely acclaimed theoretical foundation (Bandura, 1986), an extensive knowledge base (Bandura, 1997; Maddux, 1995, 2002), and a proven record of application in the workplace (Bandura, 1997, 2004; Stajkovic \& Luthans, 1998). Nine large-scale meta-analyses consistently demonstrated that the efficacy beliefs of organization members contribute significantly to their level of motivation and performance (Bandura \& Locke, 2003).

Judge et al (2007) in their research estimated the unique contribution of self-efficacy to work-related performance controlling for personality (the Big 5 traits), intelligence or general mental ability, and job or task experience. Results, based on a meta-analysis of the relevant literature, revealed that overall, across all studies and moderator conditions, the contribution of self-efficacy relative to purportedly more distal variables was relatively small. Within moderator categories, there were several cases in which self-efficacy made unique contributions to work-related performance. For example, self-efficacy predicted performance in jobs or tasks of low complexity but not those of medium or high complexity, and self-efficacy predicted performance for tasks but not for job performance. Overall, results suggested that the predictive validity of self-efficacy was attenuated in the presence of individual differences, though this attenuation does depend on the context.

Recent theory and research have begun to emphasize the role of self-efficacy in performance accomplishment. The present study attempted to examine the relationship between self-efficacy and work performance. The data were collected from 300 scientists (150 from National Dairy Research Institute, Karnal and 150 from Agriculture Extension Centers in Haryana). The results showed significant positive correlation between job specific self-efficacy and work performance. This signified that the higher the job specific self-efficacy, the higher will be the work performance of employees. Comparative analysis done to measure differences between the two groups of scientists revealed that the two groups did not difer significantly on the measures of self-efficacy and work performance.

Gist and Mitchell (1992) in their study posited that the 
construct of self-efficacy has received increasing empirical attention in the organizational behaviour literature. People who think they can perform well on a task do better than those who think they will fail. Differences in self-efficacy were associated with bona fide differences in skill level: however, self-efficacy perception also may be influenced by differences in personality, motivation, performance and the task itself. The article reviewed the antecedent processes and information cues involved in the formation of self-efficacy and how it influenced performance. A model of the determinants of self-efficacy was proposed that enhances understanding of both the complexity and the malleability of the construct. Determinants that facilitate the most immediate change in self-efficacy were identified, and appropriate change strategies were highlighted.

Stajkovic and Fred (1998) researched on the self-efficacy and work-related performance: A meta-analysis. This metaanalysis (114 studies, $\mathrm{k}=157, \mathrm{~N}=21,616)$ examined the relationship between self-efficacy and work-related performance. Results of the primary meta-analysis indicated a significant weighted average correlation between selfefficacy and work-related performance, $\mathrm{G}(\mathrm{r} \pm)=.38$, and a significant within-group heterogeneity of individual correlations. To account for this variation, the authors conducted a 2-level theory-driven moderator analysis by petitioning the $\mathrm{k}$ sample of correlations first according to the level of task complexity (low, medium, and high), and then into 2 classes according to the type of study setting (simulated-lab vs. actual-field). New directions for future theory development and research were suggested, and practical implications of the findings were discussed.

Cherian and Jacob (2013) aimed at performing a metaanalysis which analysed the individual research findings which pertained to the relationship between self-efficacy, employee motivation and work related performance of the employees. From the results of the study, it was observed that self-efficacy theory can be applied to work related performance in terms of motivating different employee related facets as well as organization pursuits. In this study the researcher attempted to assess the influence of selfefficacy on the performance of individuals at workplace and the mechanism by which self-efficacy of an individual determined his/her work related performance and motivation. Thus, it became necessary to identify the practical implications of the outcomes related to improving employee self-efficacy in order to motivate them and improve their performance.

Hurter (2008) posited that committed employees were increasingly becoming a valued asset in organizations. For the purpose of this study employee commitment was viewed as commitment to the organization as well as employees' commitment to their occupations. The purpose of the research was to determine whether there was a correlation between perceived self-efficacy and employee commitment in a South African sugar manufacturing company. Selfefficacy, a social cognition construct, which refers to a person's self-beliefs in his/her ability to perform specific tasks, has been shown to be a reliable predictor of both motivation and task performance and to influence personal goal setting. Despite this, little attention has been given to its organizational implications. The General Self-Efficacy questionnaire (GSE), and an Employee Commitment (CM) questionnaire based on the Conversion Model were used as measuring tools. The results of this study indicated that there was a positive correlation between self-efficacy and employee commitment (Ambassador, Career oriented, Company oriented). Uncommitted employees showed a lower level of self-efficacy. Further research from a predictive validity perspective was suggested in order to substantiate the findings and to improve the generalizability thereof.

According to Hax (2000) recruitment consultants today are faced with considerable stress and challenges as a result of their work. They must cope effectively with these challenges in order to deliver effective job performance, which is crucial to an organization's survival. In this study the relationship between sense of coherence, self-efficacy and job performance amongst recruitment consultants were investigated. The orientation to Life Questionnaire, Generalized Self-efficacy Scale and job performance measure comprising key performance indicators were used. The study was conducted with 99 recruitment consultants at a national recruitment organization in South Africa. While a theoretical relationship was determined, this was not supported by the empirical investigation. Relationships did, however, emerge for the comprehensibility component of sense of coherence to job performance total and for two of its dimensions (namely customer service and productivity). A regression model, comprising comprehensibility and meaningfulness, emerged as a significant predictor of total job performance.

Rubina and Azam (2004) conducted a study to explore the relationship between teachers' stress, teachers' job performance and self-efficacy of women school teachers. The study was carried out with a sample of four hundred and twenty (420) teachers selected at random at the researcher's school of choice. Results of the study showed that teachers displayed moderate level of stress and highest scores were displayed on work related stressors. Significant negative correlation was found between teachers' stress, job performance and teacher's self-efficacy. The moderated multiple regression analysis could play a moderate role in the relationship of teachers' stress and job performance.

Zellars et al (2002) conducted a research on the relationship between job related self-efficacy and withstanding organizational stress. They found that job related self-efficacy contributed to the enhancement of skill needed or necessary to cope with strenuous work in an organization, by helping the employees to accept difficult tasks in their domain as challenges to be tackled and provide possible solution to it, rather than viewing it as a tough and stressful situation. The study employed a correlational design with self-efficacy and organizational work load as the variables of consideration. The results showed that there was 
a significant relationship between high self-efficacy and ability to cope with work load.

\subsection{Implications of Previous Findings and Directions for Future Research}

1. Bandura's social cognitive theory of self-efficacy may not apply directly to performance, but may act as a factor in the midst of or combination with other factors or variables. Therefore, the extent to which self-efficacy alone, outside other factors impact on performance is not known. This is an area or line of direction for future research.

2. In all the researches examined, there seems to be no direct effect of self-efficacy on work performance.

3. Several intervening, moderating and mediating variables were discovered to be involved in the selfefficacy/work performance relationships.

4. The intervening and moderating variables included, but not limited to intelligence, the nature of the task, skill level, personality, motivation, level of the worker, supervision etc. There is therefore a need for future studies that will incorporate these variables or control them in order to obtain clearer results.

5. The summary of findings is that there is no consensus amongst researchers on the impact of self-efficacy on performance. Whereas some found a positive correlation between the variables (Hurter, 2008), others found a negative correlation (Rubina and Azam 2004) and others further found that the effect of self efficacy on performance was small and varied from task to task. (Judge et al 2007). More indepth studies are therefore needed in this direction; and the control of already identified and unidentified intervening variables and confounding variables need to be done in order to guarantee true results.

\section{Conclusion}

The review of findings on influence of self efficacy on Job performance have shown that there is no conclusive evidence on a negative or positive impact of one on the other, as several mediating variables also had a role to play.

\section{References}

[1] Bandura, A. (1977). Self-efficacy: Toward a Unifying Theory of Behavioral Change. Psychological Review, 84(2), $191-$ 215. Doi:10.1037/0033 - 295x.84.2.191.
[2] Bandura, A. (1994). Exercise of Personal and Collective Efficacy in Changing Societies. In A. Bandura (Ed.), Selfefficacy in Changing Societies (pp. 1-45). New York: Cambridge University Press.

[3] Bandura, A. (1997). Self-efficacy: The Exercise of Control. New York: Freeman.

[4] Bandura, A. (1998). Social Cognitive Theory of Personality. In L.A. Pervin \& O. P. John (Eds.), Handbook of Personality: Theory and research (2nd ed., pp. 154-196). New York: The Guilford Press.

[5] Cherian, J. \& Jacob, J. (2013). The Impact of Self Efficacy on Motivation and Performance of Employees. International Journal of Business and Management, Vol. 8, No. 14

[6] Gist, M. E. and Mitchell, T. R. (1992). Self-Efficacy: A Theoretical Analysis of its Determinants and Malleability. The Academy of Management Review Vol. 17, No. 2.

[7] Hax, G. (2010) Self Efficacy and Work related Performance: A Metaanalysis. Psychological Bulletin, 124 (2) 240-261.

[8] Hurter, N. (2008). The Role of Self-Efficacy in Employee Commitment

http://uir.unisa.ac.za/bitsream/handle/10500/2309/dissertation .pdf? sequence $=1$.

[9] Judge, T. A., Jackson, C. L., Shaw, J. C., Scott, B. A. and Rich, B. L. (2007). Self-Efficacy and Work-Related Performance: The Integral Role of Individual Differences. Journal of Applied Psychology. Vol. 92, No. 1, 107-127.

[10] Lunenburg, F. (2011). Self-Efficacy in the Workplace: Implications for Motivation and Performance. International Journal of Management, Business, and Administration, 14(1).

[11] Luszczynska, A. \& Schwarzer, R. (2008) Planning and SelfEfficacy in the adoption and maintenance of breast study examination: A longitudinal study of self-regulatory cognitions. Psychology and health, 18, 93-108.

[12] Rubina, E. \& Azam, S. A. (2004) Self Efficacy: Implication for Organizational Behaviour and Human Resource Management. Academy of Management Review, Vol 12, No 3

[13] Schwarzer, R. E. Luszczynska, A. (2007) Self-Efficacy. In M. Gerrard \& K. O. McCaul (Eds). Health Behaviour Constructs: Theory, Measurement and Research. National Cancer Institute Website. Retrieved June 11, 2008.

[14] Stajkovic, A. D. and Fred, L. (1998). Self-Efficacy and WorkRelated Performance: A Metal-Analysis. Psychological Bulletin, Vol 124(2), Sep. 1998, 240-261.

[15] Zellars, A; Donald, O. \& Taft, G. (2002) Issues in Performance and Worth of Employee's Self. Journal of Applied Psychology, 85, 765-774. 